\title{
CENTRO DE RECURSOS DE APRENDIZAGEM: BIBLIOTECA ESCOLAR PARA O SÉCULO XXI
}

\author{
LEARNING RESOURCE CENTER: \\ SCHOOL LIBRARY FOR THE XXI CENTURY
}

Kelley Cristine Gonçalves Dias Gasque $e^{1}$

Resumo: Relato de experiência do planejamento, construção e funcionamento do Centro de Recursos de Aprendizagem (CRA), do Colégio Marista de Brasília. Mais do que local de acesso à informação, constitui-se espaço de aprendizagem e de conhecimento, integrado ao processo pedagógico da escola, com a tarefa de formar cidadãos críticos e autônomos. Conclui-se que apesar do êxito da biblioteca, para que seja efetivamente usada como Centro de Recursos de Aprendizagem, a escola deve adotar currículo mais flexível e métodos de resolução de problemas.

Palavras-chave: Biblioteca escolar. Letramento informacional. Leitura. Pesquisa. Aprendizagem.

Abstract: This work reports an educational experience on planning, construction and operation processes of the Learning Resource Centre (LRC), of the Marist School, in Brasilia (Brazil). The LRC constitutes a local access to information, learning and knowledge, integrated to the school pedagogical objective of training critical and autonomous citizens. It is emphasized that, in order to be effectively used as a Learning Resource Centre, it must adopt more flexible curriculum and methodological procedures with the main task of solving problems.

Keywords: School library. Information literacy. Reading. Research. Learning.

\section{INTRODUÇÃO}

O presente trabalho é um relato de experiência do planejamento e funcionamento do Centro de Recursos de Aprendizagem (CRA), do Colégio Marista de Brasília Educação Infantil e Ensino Fundamental, inaugurado em 2001. Pretende oferecer subsídios para ampliar a discussão sobre a estrutura, função da biblioteca escolar e a relação com a concepção pedagógica adotada pela escola.

\footnotetext{
1 Doutorado em Ciência da Informação pela Universidade de Brasília e Professora adjunta da Universidade de Brasília. Brasília, DF, Brasil. E-mail: kelleycristinegasque@ hotmail.com Enviado em: 02/03/2012 - Aceito em: 10/11/2012.
} 
O Colégio Marista de Brasília é uma instituição católica, cujos princípios básicos, fundamentados na Educação Marista, inspiram uma pedagogia integral e participativa. Isso é, objetiva integrar os aspectos conceituais, procedimentais e atitudinais da aprendizagem, considerando os conhecimentos prévios, as experiências do aprendiz e a interação entre os sujeitos. Possui matriz baseada no interacionismo sócio-histórico, proposto por Vygostsky (1991) em meados do século passado, que enfatiza o papel do ambiente na aprendizagem, em que o desenvolvimento do sujeito ocorre de fora para dentro, destacando os aspectos sociais.

Nessa perspectiva, a aprendizagem transcende a simples memorização dos fatos e fixação gradual de hábitos de autocontrole, atenção, aprendizado mnemônico e imitação de habilidades (SHOOK, 2002). O aprendiz, com a orientação de um mediador, deve atuar ativamente em prol do próprio aprendizado, desenvolvendo competências, habilidades e atitudes para aprender a lidar com o aumento exponencial da informação, transformando-a em conhecimento necessário a uma vida digna, como preconiza o relatório para a UNESCO da Comissão Internacional sobre Educação para o século XXI (DELORS, 1998).

A biblioteca escolar do Colégio Marista de Brasília desempenha papel crucial no processo de ensino-aprendizagem, devendo atuar como Centro de Recursos de Aprendizagem (CRA) integrado à proposta pedagógica da escola. No entanto, isso implica, por sua vez, a adoção, pela escola, de estratégias de aprendizagem que privilegiem a pesquisa, a resolução de problemas e o protagonismo do aprendiz. Com o objetivo de apresentar como o CRA se insere nessa proposta, nos próximos tópicos são abordados a fundamentação teórica, a motivação para a criação do novo espaço de aprendizagem, o lay-out do projeto e as competências do bibliotecário para atuar nesse espaço.

\section{A BIBLIOTECA COMO CENTRO DE RECURSOS DE APRENDIZAGEM}

O projeto da nova Biblioteca do Colégio Marista de Brasília norteou-se pela perspectiva da Integração pedagógica, em que se deve atuar como Centro de Recursos de Aprendizagem interligado ao processo pedagógico da escola, em consonância com o currículo e a concepção pedagógica da escola. Para tanto, o espaço conta com infraestrutura adequada de informação que abrange acervo atualizado e informatizado, 
acesso à internet e bancos de dados, espaços de leitura, pesquisa e atividades culturais, políticas de uso dos espaços e dos recursos, além de lay-out e estratégias que propiciem a aprendizagem reflexiva e colaborativa.

Dessa maneira, o foco da biblioteca centra-se no paradigma de Integração Pedagógica, sem excluir o paradigma de Acesso à informação. Isso pressupõe acesso dos usuários à estrutura de informação com serviços e produtos de qualidade, bem como a mediação que os auxilie a transformar informação em conhecimento. O paradigma de acesso à informação, nesse relato, focaliza especificamente a estrutura e a disseminação de informação, em detrimento dos processos de aprendizagem que, por ventura, possam ocorrer. Assim, os paradigmas supracitados completam-se mutuamente, não se limitando à estrutura física, ainda que não a excluindo, pois se constitui recurso didático importante.

O paradigma de integração pedagógica requer compreender a biblioteca escolar atuante como Centro de Recursos de Aprendizagem, isto é, como instituição que organiza materiais bibliográficos, audiovisuais e outros meios e os coloca à disposição da comunidade educacional, constituindo-se parte integral do sistema educativo e participando de seus objetivos, metas e fins. A biblioteca escolar é instrumento de desenvolvimento do currículo, que permite o fomento à leitura e à formação de uma atividade científica. Torna-se, portanto, elemento crucial na formação do indivíduo para a aprendizagem permanente, estimulo à criatividade e à comunicação. Facilita o acesso às atividades culturais, apóia os docentes em sua capacitação e lhes oferece a informação necessária para a tomada de decisão em aula. Trabalha também com os pais de família e com outros agentes da comunidade (ORGANIZAÇÃO DOS ESTADOS AMERICANOS - OEA, 1985).

O referido conceito de biblioteca escolar atuante como Centro de Recursos de Aprendizagem foi sintetizado na publicação "Modelo Flexível para um Sistema Nacional de Bibliotecas Escolares" (ORGANIZAÇÃO DOS ESTADOS AMERICANOS-OEA, 1985, p. 22) e orientou o planejamento e a implementação de serviços e oferta de produtos na Biblioteca do Colégio Marista de Brasília. Para melhor compreensão do conceito, estabelece-se breve paralelo entre o que o modelo preconiza e como tais questões são tratadas na Biblioteca do Colégio Marista de Brasília, 
denominada pela comunidade educacional de CRA - Centro de Recursos de Aprendizagem.

\section{Acesso à informação}

O primeiro ponto a destacar no conceito sintetizado pela OEA refere-se à biblioteca como espaço de armazenamento e disseminação da informação, motivo pelas quais foram criadas. Historicamente, as primeiras bibliotecas foram concebidas sob o paradigma da conservação (KEIKO, 1997), cujo objetivo era assegurar a preservação e conservação dos materiais. Contudo com a criação da imprensa, a inclusão das bibliotecas nas políticas públicas e o aprimoramento das competências técnicas, as bibliotecas começam a ser concebidas com a finalidade de disseminar informação, constituindo o paradigma da difusão.

Reconhece-se o CRA do Colégio Marista de Brasília como espaço de organização da informação, que propicia, de maneira rápida e fácil, a recuperação de informações necessárias à comunidade. O CRA atende aprendizes de 3 a 15 anos, pais, professores e funcionários do colégio, motivo pelo qual se optou por representar os assuntos do acervo, genericamente, por meio da Classificação Decimal de Dewey (CDD). Para a classificação do autor, a regra geral é usar as primeiras cinco letras do sobrenome do autor, seguidas pelas duas letras iniciais do título, desconsiderando os artigos definidos e indefinidos. $\mathrm{O}$ objetivo dos procedimentos descritos é facilitar o acesso à informação por diferentes faixas etárias. Além disso, as estantes são sinalizadas com a descrição dos assuntos a serem encontrados em cada uma delas.

O Pergamum, sistema de informação desenvolvido pela PUCPR/PUCRIO e selecionado pela mantenedora da rede de bibliotecas escolares da província Marista Centro-Sul, na qual se insere o CRA do Colégio Marista de Brasília, foi implantado a partir de 2003. O sistema apresenta vantagens como interoperabilidade de dados ${ }^{2}$, uso de padrões internacionais de catalogação e intercâmbio dos dados, possibilidade de processamento técnico de recursos diversificados de informação, a reutilização do banco de autoridades criado pelas bibliotecas para o processo técnico do acervo, dentre outras. A desvantagem principal do sistema refere-se à sua complexidade, o que requer formação mais consistente do bibliotecário e dos usuários (estudantes) do sistema.

\footnotetext{
${ }^{2}$ Capacidade do sistema de trocar dados com outros sistemas por meio da adoção de padrões. 
O acesso à informação vincula-se a uma estrutura informacional adequada, com acervo organizado, diversificado e atualizado. Por sua vez, encontrar informação relevante e pertinente e transformá-la em conhecimento requer o engajamento do indivíduo no processo de aprendizagem.

2.2 A biblioteca escolar sob a perspectiva sistêmica: leitura, pesquisa e formação docente

A OEA (1985) ressalta a importância da integração das bibliotecas escolares ao sistema educacional. Historicamente, no Brasil, as bibliotecas escolares têm sido negligenciadas e, muitas vezes, atuam como apêndices do sistema educacional (GASQUE; COSTA, 2003). Para favorecer essa integração, uma das estratégias utilizadas no CRA do Colégio Marista de Brasília é a parceria com a coordenação pedagógica e os professores da instituição, por meio da participação no planejamento anual e semanal com os professores de cada ano e/ou segmento. Em geral, ao final do ano letivo, vislumbram-se os projetos a serem realizados com os diversos segmentos da escola, os quais devem constar no planejamento pedagógico anual. Ao longo do ano, são possíveis ajustes e inserção de novos projetos e eventos para complementar e ampliar os assuntos tratados em sala de aula. Essas atividades abrangem desde a seleção de materiais de leitura aos eventos culturais que promovem a leitura e pesquisa.

No Colégio Marista de Brasília, os primeiros projetos de fomento à leitura, em geral, refletiam situações episódicas ou projetos pessoais dos professores, com uma linguagem não unificada e insuficiente como identidade institucional. Ao reconhecer tal problema com relação à leitura, articulou-se um projeto comum e sistematizado para formação do leitor competente, consistindo em: a) desenvolver estratégias diversificadas de leitura e compreensão de diferentes gêneros textuais em todas as disciplinas do currículo; b) graduar o trabalho com gêneros e textos, em Língua Portuguesa, nas diferentes séries; c) estabelecer metas literárias ao longo das séries; d) ampliar as habilidades (compreensão, rapidez) de leitura dos professores e alunos; e) expandir o vocabulário e melhorar a ortografia; f) possibilitar contato mais estreito com obras e autores diversificados da literatura infantil e, g) favorecer o uso dos recursos e serviços do CRA.

O estabelecimento de objetivos mensuráveis e monitoração do processo possibilitaram o amadurecimento do projeto de leitura e a melhoria do desempenho dos 
aprendizes. Nessa proposta, o CRA contribui com a formação do leitor ao selecionar, adquirir, organizar e divulgar material de literatura, em consonância com o interesse das várias faixas etárias dos estudantes e ao promover eventos culturais e literários. Dentre os vários mini-projetos de leitura realizados anualmente, destaca-se o "Encontro Literário Champagnat", que celebra, de forma significativa, o encontro dos leitores com as obras literárias e os respectivos autores. Ziraldo, Pedro Bandeira, Lygia Bojunga, Stella Maris Rezende, dentre outros, foram convidados a trocar informações com os leitores sobre uma obra selecionada e lida previamente.

Adicionalmente, cabe ao CRA, a organização semanal da "hora do conto" para os alunos da educação infantil ao $5^{\circ}$ ano do ensino fundamental, que atualmente consta na grade curricular da escola. Na "hora do conto", os aprendizes desenvolvem competências e habilidades importantes para a leitura, por exemplo, identificar as características das obras; conhecer as obras e autores renomados de literatura infantil e infanto-juvenil, identificar estilos diversificados dos autores; reconhecer vários gêneros literários - contos, crônicas, poesias, etc. e os elementos que os compõem; desenvolver o juízo e os valores estéticos; bem como aprender sobre o funcionamento da biblioteca.

Com o objetivo de facilitar o contato com as obras de literatura foram adotados kits de literatura para compor a "biblioteca de sala de aula", em que os estudantes compram 2 ou 3 livros indicados pelo colégio no início do ano letivo. A leitura dos livros do Kit, obrigatória para os estudantes, é avaliada por meio de atividades lúdicas. Apesar de as "bibliotecas de salas de aula" possibilitarem o contato rápido com as obras, muitas vezes, são utilizadas como o único canal de leitura. Alguns professores preferem usar o kit de leitura da sala para evitar as saídas e obter mais tempo para trabalhar outros conteúdos. Mesmo com avaliações demonstrando que as visitas semanais das turmas para empréstimo de livros propiciam competências cruciais ao leitor, ainda assim, muitas turmas se restringem à leitura dos títulos anuais sugeridos pela escola, em detrimento de 37.000 títulos do CRA, atualizados e informatizados. Como resposta ao problema, buscou-se conscientizar os professores sobre a importância de equilibrar o uso dos recursos do Kit de leitura e do CRA. 
A formação para a pesquisa ou processo de letramento informacional ${ }^{3}$ é promovida com o auxílio de alguns professores, mas são casos pontuais e com pouca abrangência. Isso porque, apesar das inovações propiciadas pela escola, algumas estratégias de ensino-aprendizagem permanecem tradicionais. Alguns professores se limitam a 'passar o conteúdo' para os alunos em aulas predominantemente expositivas, devido à quantidade de conteúdos a serem trabalhados no decorrer do ano letivo. Deste modo, os aprendizes usam quase exclusivamente os livros didáticos ou paradidáticos indicados pela escola, recorrendo pouco a outras fontes de informação.

Além disso, grande parte dos professores não aprendeu a usar bibliotecas e produzir pesquisas. Isso porque a formação do professor no Brasil nem sempre abrange a dimensão problematizadora. O paradoxo ocorre quando o professor tenta ensinar por meio de projetos ou resolução de problemas, quando eles próprios desconhecem metodologias de investigação. Portanto, os docentes pouco estimulam os aprendizes a frequentar a biblioteca e a pesquisar, prejudicando, muitas vezes, o desenvolvimento do pensar autônomo e reflexivo.

Mais do que formar o gosto pela leitura e desenvolver competências para pesquisar, a biblioteca atuante como Centro de Recursos de Aprendizagem deve ser local de ação cultural, propício a eventos como palestras, debates, recitais de poesias, concursos, exposições de artistas, lançamentos de livros, hora do conto e oficinas de artes. As atividades culturais estimulam a criatividade, facilitam a recreação e podem ser utilizadas como recursos de marketing. O CRA utiliza os eventos para expandir os conhecimentos da comunidade educacional, bem como estimular o uso do espaço. Desde a inauguração do CRA, têm sido realizadas, em média, três grandes exposições anuais, tais como: "Centenário de Drummond", "A poesia de Quintana"; "Hans Christian Andersen"; "Maquetes de grandes batalhas"; "Folclore Brasileiro"; exposições de artistas brasilienses e oficinas de leitura.

Em relação ao apoio aos docentes em sua capacitação para a tomada de decisão em sala de aula são promovidos empréstimos de livros, seleção e divulgação de materiais de interesses do professor; suporte ao ensino-aprendizagem mediante aos debates sobre temas educacionais e formação de grupos de estudo. Na medida do

\footnotetext{
3 Estruturação sistêmica de um conjunto de competências que possibilita integrar as ações de localizar, selecionar, acessar, organizar e gerar conhecimento (GASQUE; CUNHA, 2010)
} 
possível, quase sempre de forma não sistematizada, realiza-se a capacitação dos professores para trabalhar com as várias fontes de informação. O pressuposto é de que o professor deve atuar como elemento multiplicador junto aos aprendizes, visto que as ações desenvolvidas em parceria com os professores são mais eficazes e abrangentes do que aquelas voltadas especificamente para os aprendizes.

O último ponto do conceito refere-se ao envolvimento da comunidade educativa de maneira que se institucionalize uma cultura de uso da biblioteca escolar. Para tanto, além das atividades descritas, os projetos "Pais e escolas Refletindo..." e "Informar" possibilitam reunir grande parte dos pais e educadores do colégio. O primeiro projeto constituído por um ciclo bimestral de palestras, proferidas por "grandes nomes" da área, aborda temas voltados à educação como: relação pais-filhos, limites, drogas, dificuldades de aprendizagem. O projeto congrega por volta de 600 pessoas por evento. Por se tratar de evento de médio porte e com custos altos, o projeto foi organizado e financiado, durante alguns anos, por cinco escolas católicas de Brasília. O projeto Informar, de menor porte, consiste de palestras e debates mensais sobre saúde, administração, direito e outros temas, complementando o evento "Pais e Escolas Refletindo...". No projeto Informar, os palestrantes são profissionais liberais interessados em apresentar seu trabalho para a comunidade marista, que por sua vez, tem interesse em discutir temas que os ajudem no cotidiano. Constitui-se em uma atividade que requer poucos recursos, com muitos benefícios aos envolvidos no programa.

O conceito de biblioteca escolar atuante como Centro de Recursos de Aprendizagem é fundamental para se ter uma abordagem sistêmica e integrada à comunidade educacional. Nessa abordagem, a estrutura (arquitetura, lay-out, mobiliários, recursos e produtos) constitui-se elemento fundamental. Grande parte do êxito do CRA do Colégio Marista de Brasília se deve aos investimentos da escola, que garantem a manutenção e a renovação da estrutura de informação, descrita no próximo tópico. 


\section{PROJETO E CONSTRUÇÃO DO CENTRO DE RECURSOS DE APRENDIZAGEM}

O projeto do Centro de Recursos de Aprendizagem surgiu em decorrência dos bons resultados do trabalho desenvolvido na biblioteca antiga da referida escola, a qual precisava se expandir para reduzir as reclamações dos professores em relação às limitações de espaço físico, funcionários e equipamentos. O projeto partiu da reforma e ampliação de uma construção existente na escola, norteado por duas premissas:

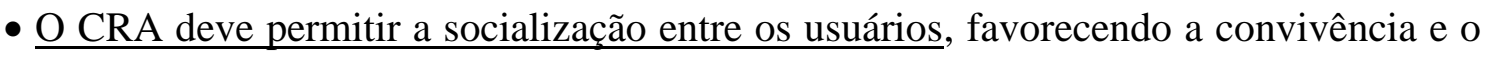
respeito entre colegas de faixas etárias diferentes. Os ambientes foram construídos em consonância com as funções desenvolvidas no espaço: atividades culturais, literatura e pesquisa.

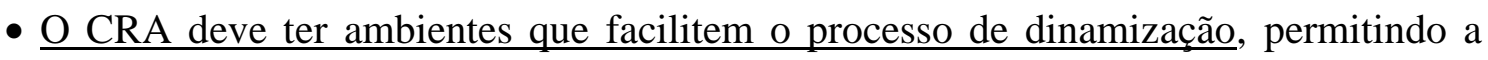
ocorrência de várias atividades simultaneamente, em ambientes amplos, confortáveis e com múltiplos recursos educacionais.

\section{Características gerais do programa}

Em linhas gerais, o CRA foi planejado para ser um convite à leitura, à pesquisa e ao lazer, com fácil acesso e proteção das intempéries climáticas. As salas amplas, bem iluminadas e confortáveis, com diferentes cores permitem criar sensações diferenciadas em cada espaço. O acervo fica à disposição, devidamente sinalizado aos estudantes, professores, funcionários e pais, que possuem livre acesso às estantes.

O projeto visa à redução do vandalismo e o favorecimento do auto-atendimento. Para isso, as estantes e demais mobiliários situam-se em espaços que propiciam visão ampla dos aprendizes aos funcionários das ilhas de atendimento. Adicionalmente é utilizado sistema de filmagem interna para auxiliar a monitoração do local. O CRA conta com elevador para usuários com necessidades especiais e monta-carga para transporte dos livros.

O CRA oferece atendimento das $7 \mathrm{~h} 30$ às $19 \mathrm{~h}$ ininterruptamente para aproximadamente 2800 estudantes e respectivas famílias, professores e funcionários. Os estudantes utilizam o espaço para estudos, pesquisas e leituras no horário contrário aos das aulas, ou durante as aulas, quando acompanhados pelos professores. 
No projeto foram consideradas as atividades funcionais e técnicas, por exemplo, produção de ruído, material de fácil limpeza, necessidade de iluminação artificial, ventilação e controle de umidade, tomadas de equipamentos, sanitários e água, medidas contra riscos de incêndio e isolamento acústico.

A organização do espaço

O CRA conta com aproximadamente $1400 \mathrm{~m} 2$, divididos em três andares, conforme descrição a seguir:

No térreo, situa-se o espaço de acolhimento/empréstimo, composto pelas salas de guarda-volumes e de empréstimo, em que se localizam o servidor e o equipamento de controle e distribuição de som para os ambientes. Destina-se a fornecer informações gerais; agendamento de horários para uso dos espaços e equipamentos; empréstimo/devolução e armazenamento temporário dos materiais devolvidos. Nesse espaço, funcionam também os serviços de recebimento e conferência de livros, periódicos e outros materiais.

Em seguida, no mesmo andar, encontra-se o Centro Cultural, com aproximadamente $153 \mathrm{~m}^{2}$, "palco" de uma programação rica e diversificada como exposições, lançamentos de livros, palestras e oficinas. $\mathrm{O}$ espaço possui recursos como expositores para livros, expositores para materiais não manuseáveis, canais de TV a cabo, data-show e tela elétrica. A figura 1 mostra exposição ocorrida no espaço cultural.

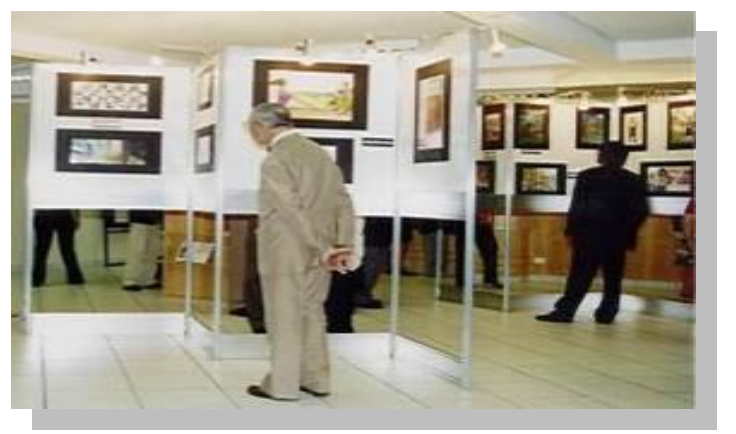

Figura 1: Exposição de Jô Oliveira - Centro Cultural do CRA/Colégio Marista de Brasília ${ }^{4}$

Entre o térreo e primeiro piso, localiza-se o ambiente de higienização, com banheiros e bebedouros. No $1^{\circ}$ Piso, localiza-se o Espaço da leitura, composto pela sala de coordenação, videoteca, mapoteca, hemeroteca, sala da "hora do conto" e salão de

\footnotetext{
${ }^{4}$ Fonte: Acervo do Colégio Marista de Brasília.
} 
leitura, como se observa na figura 2. O Espaço da leitura conta com o acervo de literatura infanto-juvenil, brasileira, estrangeira, bem como a seção de periódicos. Nesse andar, em uma sala de $25 \mathrm{~m}^{2}$, ocorre a "hora do conto" para as turmas da educação infantil ao $5^{\circ}$ ano, com o desenvolvimento de atividades artísticas como origami, pintura, colagem e jogos.

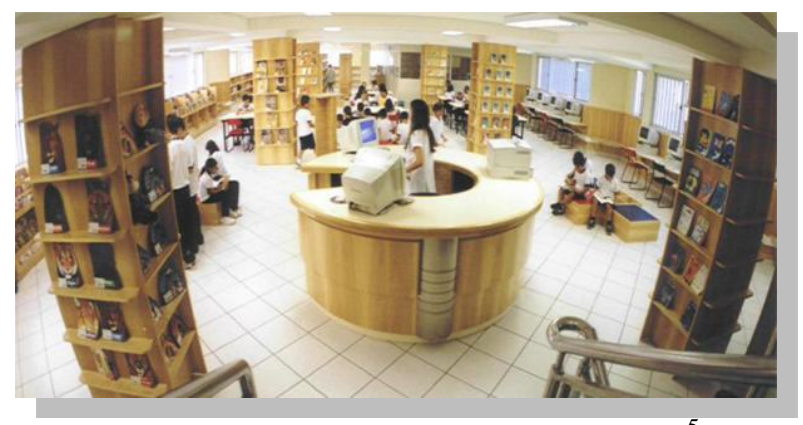

Figura 2: visão panorâmica do $1^{\circ}$ piso $^{5}$

O acesso à videoteca, local para armazenamento de fitas VHS, fitas cassetes, slides, CDs, periódicos antigos, fotografias dos eventos da escola, é permitido somente aos funcionários e professores.

A madeira utilizada nos mobiliários do CRA é o pau-marfim, com fórmica nata nas mesas e bancadas. Nas almofadas e cadeiras de corino - couro sintético - estão presentes as cores azuis e vermelhas, em contraste com o tom marfim. Para o aproveitamento total do espaço, os pilares, com função estrutural, foram revestidos com placas de madeira de $1,5 \mathrm{~cm}$ e prateleiras horizontais a cada $30 \mathrm{~cm}$ para expor as obras impressas. As paredes cobertas com lambris de pau-marfim, com altura de 1,5 m conferem fluidez e aconchego ao ambiente.

As estantes de livros, de acordo com as recomendações de Gascuel (1987, p. 79), devem ser estáveis e resistentes e possuir suportes reguláveis, com prateleiras que suportam o peso dos livros $(80 \mathrm{~kg} / \mathrm{m})$. As estantes do CRA, produzidas em pau-marfim com prateleiras revestidas de fórmica branca e brilhante, resistem ao atrito provocado pela manipulação freqüiente dos livros. Os fundos das estantes não possuem divisórias, facilitando a visão dos usuários que transitam entre elas. As estantes foram produzidas em duas alturas: a infantil com altura de 1,35; e as demais com 1,85 cm.

\footnotetext{
${ }^{5}$ Fonte: Acervo do Colégio Marista de Brasília. 
No segundo piso, figura 3, situa-se o Espaço de documentação, constituído pelo ambiente de pesquisa - salão com mesas de estudo, 10 cabines de aproximadamente $10 \mathrm{~m}^{2}$ com acomodações para até 7 usuários em cada cabine e 3 cabines individuais. As cabines são equipadas com microcomputadores multimídias com acesso à internet, drive de CD, DVD e recursos de rádio e TV. No espaço central, distribuem-se 12 mesas para acomodar 48 pessoas. Para dar suporte aos usuários que não pretendem fazer pesquisas em documentos impressos, encontra-se uma bancada com 12 computadores, cujo tempo máximo de pesquisa é de 50 minutos, com possibilidade de renovação.

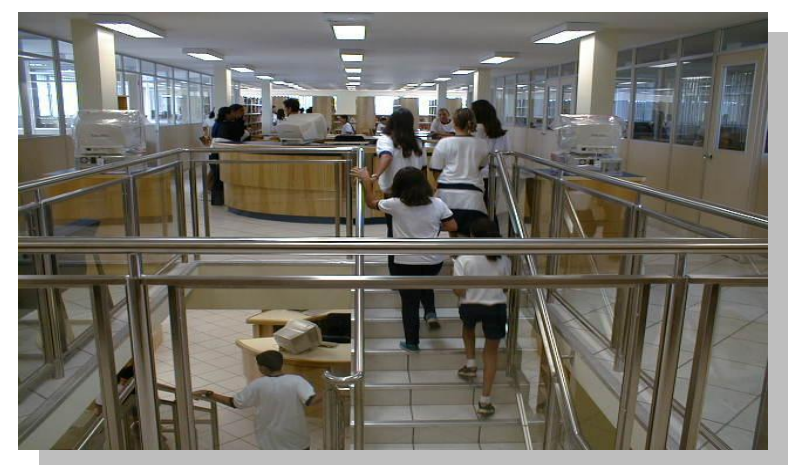

Figura 3: visão panorâmica do segundo piso (espaço da documentação): ilha de atendimento, cabines laterais e espaço central ${ }^{6}$

Escolheu-se a cor azul petróleo para a fórmica dos tampos das mesas, bancadas e balcões. As cadeiras e as divisórias das cabines são beges. As estantes de madeira se concentram ao final do salão.

Ao lado do espaço da documentação situa-se a sala Champagnat, espaço multiuso com capacidade para acolher aproximadamente 200 pessoas. Nesse local, ocorrem palestras, oficinas e eventos. Uma das atividades que ocorrem mensalmente nesse local é o projeto CINEMAR, em que são escolhidos filmes para debates e fruição dos alunos. Muitas vezes, os filmes são recomendados pelos professores, com o objetivo de ampliar o assunto estudado em sala de aula.

Com a construção da nova biblioteca, verifica-se que uma boa estrutura de informação exerce grande atração aos usuários, mas a fidelização deles ocorre quando a biblioteca atua como Centro de Recursos de Aprendizagem. Isso significa que a estrutura de informação precisa ser dinamizada e planejada como parte integrante da concepção pedagógica, o que por sua vez, requer que o bibliotecário atue como 
infoeducador, isto é, que auxilie os aprendizes a lidarem com a informação para transformá-la em conhecimento aplicável.

Nesse sentido, de acordo com a Lei no 12.244 - Universalização das bibliotecas escolares no Brasil, as escolas públicas e privadas devem ter bibliotecas administradas por profissionais com bacharelado em Biblioteconomia. Contudo, é importante ressaltar que os cursos de graduação de biblioteconomia, muitas vezes, oferecem uma formação mais generalista, com pouca ênfase na compreensão dos processos de ensino-aprendizagem e na prática pedagógica. Sugere-se, para tanto, com base nas experiências expostas nesse relato, uma matriz de competências que direcione a formação do bibliotecário escolar para atuar de forma efetiva e eficiente nos Centros de Recursos de Aprendizagem.

\section{AS COMPETÊNCIAS DO BIBLIOTECÁRIO ESCOLAR - INFOEDUCADOR}

Formação profissional diz respeito ao processo de desenvolvimento contínuo para a aquisição de conhecimentos, atitudes e competências gerais. De acordo com Imbernón (1994), a formação inicial refere-se à aquisição de conhecimentos de base; e formação continuada ou permanente abrange a formação após a aquisição de base, com caráter de aperfeiçoamento ao longo de toda a vida profissional.

Apesar de a educação básica influenciar muito a formação dos bibliotecários, o foco desse relato centra-se nas competências adquiridas no curso de graduação de Biblioteconomia, formação em serviço e cursos de pós-graduação, bem como cursos não sistematizados como participações em palestras, oficinas, dentre outros.

Em primeiro lugar, cabe destacar que conhecimento e competência são conceitos diferentes. Competência remete à ideia de funcionalidade e aplicação do conhecimento. Por exemplo, conhecer bem os sistemas de classificação e as normas de catalogação não são suficientes para o bibliotecário ser considerado competente. Porém, ele demonstra competência ao usar o conhecimento para projetar sistemas que facilitem o acesso e a recuperação da informação dos usuários. Portanto, competência envolve conhecimento, atitudes e o saber fazer iluminados pela teoria e reflexão sobre a prática.

A formação dos bibliotecários atuantes nos Centros de Recursos de

\footnotetext{
${ }^{6}$ Fonte: Acervo do Colégio Marista de Brasília.
}

\begin{tabular}{l|l|l|l|l|l|l} 
(C) Rev. digit. bibliotecon. cienc. inf. & Campinas, SP & v.11 & n.1 & p.138-153 & jan./abr. 2013 & ISSN 1678-765X \\
\hline
\end{tabular}


Aprendizagem deve abranger quatro competências básicas, quais sejam:

- Técnica: refere-se aos conhecimentos necessários para o domínio das tecnologias - saber fazer e o tratamento do fluxo documental, por exemplo, avaliar, selecionar, adquirir, classificar, catalogar, indexar, disponibilizar e recuperar informações, considerando as especificidades da educação básica.

- Gerencial: refere-se aos conhecimentos que possibilitam a gestão das tarefas de um grupo ou organização, tais como comprar materiais; contratar recursos humanos; definir funções dos funcionários/membros e monitorá-los; planejar o marketing e as atividades de rotina; avaliar o desempenho, dentre outros.

- Psicopedagógica: refere-se às áreas abrangidas pela pedagogia e psicologia com referência ao processo de aprendizagem - estilos, modalidades - tendo como foco aprendizes de 3 a 17 anos. A aquisição desse conhecimento possibilita ao bibliotecário criar ambiente social favorável à aprendizagem; estimular o pensamento crítico; orientar os aprendizes a buscar e usar a informação; produzir projetos em parceria com os professores, incentivar a leitura e a pesquisa, orientar sobre o plágio, orientar a formação dos professores pesquisadores, dentre outros.

- Social: refere-se ao conhecimento que permite aprimorar as relações humanas, tais como, mediar conflitos, estimular o trabalho em grupo, planejar atividades culturais, aperfeiçoar os feedback aos membros do grupo.

Tradicionalmente, os núcleos técnicos e gerencial estão no cerne da formação dos bibliotecários. Contudo, mais do que nunca, a visão transdisciplinar é necessária à atuação do bom professional, ao reconhecer que o acesso à informação é somente o primeiro passo para aquisição do conhecimento. Por isso, é necessário ensinar os aprendizes a buscar informações e transformá-las em conhecimento. Isso requer desenvolver competências pedagógicas e sociais.

Os riscos de uma biblioteca gerenciada por bibliotecários sem a formação adequada podem abranger, dentre outros, o autismo do bibliotecário/biblioteca; problemas de comunicação entre docentes e bibliotecários; incompreensão dos processos de ensino-aprendizagem que ocorrem em sala de aula; incompreensão do papel da biblioteca escolar; apêndice do sistema educacional com pouco 
reconhecimento; desconhecimento das inovações pedagógicas e serviços e produtos descontextualizados.

Em suma, as competências básicas para o bibliotecário atuar como infoeducador precisam abranger os aspectos psicopedagógicos e sociais, além dos técnicos e gerenciais. Destaca-se que, primeiramente, a motivação para a formação continuada deve emergir do próprio bibliotecário. Evidentemente, isso não tira a responsabilidade das universidades de oferecerem ensino-aprendizagem voltado para as especificidades da biblioteca escolar, bem como da formação em serviço a serem oportunizadas pelo sistema educacional aos bibliotecários, assistentes e auxiliares da biblioteca.

\section{CONCLUSÃO}

No início do relato, apresentou-se o conceito da biblioteca escolar atuante como Centro de Recursos de Aprendizagem, paradigma que fundamenta o CRA do Colégio Marista de Brasília. Os investimentos realizados na estrutura e na formação de recursos humanos têm sido cruciais para o êxito do CRA. Atualmente, o espaço recebe educadores e bibliotecários de diversos locais do Brasil para conhecer o espaço e os projetos desenvolvidos.

Contudo, apesar da caminhada de sucesso, um ponto crucial para que a biblioteca do Colégio Marista de Brasília seja efetivamente usada como Centro de Recursos de Aprendizagem implica a adoção de um currículo mais flexível, em que os professores estimulem a investigação científica ou que adotem, de maneira geral, os métodos de resolução de problemas. Nessa perspectiva, a formação do professor como pesquisador torna-se fundamental.

A biblioteca como Centro de Recurso de Aprendizagem insere-se no "Paradigma de Integração Pedagógica" que a considera parte integrante do processo educacional. Logo, o foco deve-se centrar nos processos de letramento informacional que ocorrem nesse espaço, que designam, grosso modo, a formação de competências para lidar com a informação. Isso porque se observa forte conexão entre o Paradigma da Integração Pedagógica e a concepção de ensino-aprendizagem. Escolas com currículo flexível e globalizado que estimulam o raciocínio e a construção de competências por meio da resolução de problemas, naturalmente favorecem o uso de múltiplos autores e fontes diversificadas de informação. 


\section{REFERÊNCIAS}

DELORS, Jacques et al. Educação: um tesouro a descobrir. São Paulo: Cortez; Brasília, DF: MEC:UNESCO, 1998. Disponível em: <http://unesdoc.unesco.org/images/0012/001298/129801por.pdf >. Acesso em: 3 jan. 2010 .

GASQUE, Kelley Cristine G. D. ; CUNHA, Marcus Vinícius da . A epistemologia de John Dewey e o letramento informacional. Transinformação, v. 22, p. 139-146, 2010. Disponível em: http://revistas.puc-campinas.edu.br/transinfo/viewarticle.php?id=355. Acesso em: 11 mar. 2011.

GASQUE, Kelley Cristine G. D. ; SOUZA, C. S. M. Comportamento dos professores da educação básica na busca da informação para formação continuada. Ciência da Informação (Impresso), Brasília, v. 32, p. 54-61, 2003. Disponível em: < http://www.scielo.br/pdf/ci/v32n3/19024.pdf>. Acesso em: 11 mar. 2011.

GASCUEL, Jacqueline; Barroso, Maria Ines. Um espaco para o livro: como criar, animar ou renovar uma biblioteca. Lisboa: Publicacoes Dom Quixote, 1987. 301 p. Titulo original: Un espace pour le livre.

IMBERNÓN, Francisco. La formación del professorado. Buenos Aires : Paidós, 1994.

KEIKO, Regina. Biblioteca interativa: concepção e construção de um serviço de informação em ambiente escolar. - USP: São Paulo, 1998.

ORGANIZAÇÃO DOS ESTADOS AMERICANOS. Modelo flexível para um sistema nacional de bibliotecas escolares. Brasília: FEBAB, 1985.

SHOOK, John R. Os pioneiros do pragmatismo americano. Rio de janeiro: DP\&A, 2002.

VYGOTSKY, Lev. Pensamento e Linguagem. São Paulo: Martins Fontes, 1991. 


\section{Agradecimentos:}

Agradeço as pessoas que acreditaram e investiram no CRA do Colégio Marista de Brasília. Agradeço também aos professores Isabel Cristina Michelan de Azevedo e Ricardo Tescarolo pela leitura e sugestões.

\section{Ficha técnica de 2001:}

Diretor Pedagógico da Província Marista de São Paulo: Ricardo Tescarolo

Diretor Geral do Colégio Marista de Brasília: Irmão Paulo Antonio Forster Ramos

Diretor Administrativo do Colégio Marista de Brasília: Orivaldo Pincinato

Diretora Educacional do Colégio Marista de Brasília: Cláudia Regina Princhak Teixeira Pinto

Concepção geral do Projeto e Lay-out do CRA: Kelley Cristine Gonçalves Dias Gasque Projeto de rede do CRA: Angelo Martinelli

Construtora: A. Yoshii

\section{Como citar este relato:}

GASQUE, Kelly Cristine Gonçalves Dias. Centro de recursos de aprendizagem: biblioteca escolar para o século XXI. Rev. digit. bibliotecon. cienc. inf., Campinas, SP, v.11, n.1, p.138-154, jan./abr. 2013. ISSN 1678-765X. Disponível em: <http://www.sbu.unicamp.br/seer/ojs/índex.php>. 